\title{
An Investigation of Real Estate Investment Decision-Making Practices
}

\author{
Edward J. Farragher* and Arline Savage**
}

\begin{abstract}
This survey investigation reports on the investment decision-making processes used by equity investors in real estate. The survey covers the entire investment decisionmaking process, from setting strategy to auditing operating performance. Respondents identify the most important stages of the process as searching for investment opportunities, forecasting expected returns, and evaluating forecasted returns. Most believe that individual project factors are more important than strategic and portfolio factors, and that returns should be measured on a before-tax cash flow basis and evaluated using discounted cash flow measures. Respondents are more concerned with project than portfolio risk and are unlikely to make a quantitative risk assessment or risk adjustment. When compared with the results of earlier studies, this investigation suggests that real estate investment decisionmaking practices have not evolved much over the past decade.
\end{abstract}

Since the mid-1970s, many researchers (Wiley, 1976; Farragher, 1982; Page, 1983; Webb, 1984; Webb and McIntosh, 1986; Louargand, 1992; Farragher and Kleiman, 1996) have explored the extent to which equity investors in income-producing real estate use rigorous investment decision-making practices. Although the studies ask different questions, provide different ways of answering these questions, and survey different populations, their results suggest that real estate investment decision-making has become more sophisticated over time. More specifically, these studies indicate that:

- Most financial evaluations consider returns over an investment's intended holding period, rather than merely considering performance for the first year;

- Returns are forecast on a cash rather than an income basis;

- Before-tax returns are used more often than after-tax returns, especially for REIT and pension fund investors;

- Rate of return on equity is used more often than rate of return on total purchase price;

- Most investors use discounted cash flow evaluation measures;

- Investors tend to use naïve risk assessment measures (debt coverage ratio, default ratio, breakeven point) rather than the more sophisticated measures (sensitivity analysis, scenario analysis) advocated by academics; and

\footnotetext{
* Oakland University, Rochester, MI 48309-4493 or farraghe@oakland.edu.

**California Polytechnic State University-San Luis Obispo, San Luis Obispo, CA 93407 or savage@calpoly.edu.
} 
- Quantitative risk adjustment usually involves adjusting the discount rate and adjustments are most often made on a subjective rather than analytical basis.

This paper updates earlier studies by reporting the results of a 2005 mail survey of the real estate investment decision-making processes used by large institutional investors (REITs, pension funds, and life insurance companies) and private investment and/or development organizations. The survey instrument is similar to the one used in the 1996 Farragher and Kleiman study. Consequently, comparison of these two studies yields a 10-year historical perspective of the evolution in real estate investment decision-making. For real estate investors, the results provide an updated benchmark against which to compare their investment decision-making practices. For academics, this updated view of the processes and analytical tools currently in use may help them design real estate investment courses aimed at improving future real estate investment decision-making practices.

\section{Research Design and Data}

Data was collected from responses to a questionnaire mailed to chief investment officers at 807 United States-based companies that develop and/or invest in incomeproducing real estate. The mailing list included 106 institutional investors (REITs, pension funds, and life insurance companies) and 701 private investment and/or development companies. The sample was developed from the following sources:

- Pension \& Investment, Top 50 Managers of Real Estate Assets (2004);

- National Real Estate Investor, Top 25 Office Developers (2004), Top 25 Office Owners (2004), Top 25 Industrial Developers (2004), Top 25 Industrial Owners (2004), Top 25 Industrial Developers (2004), Top 25 Hotel Owners (2004), Top 25 Apartment Owners (2004);

- National Multi Housing Council, 50 Largest U.S. Apartment Owners (2004);

- REITnet, REITs with an Equity Focus (2004);

- Urban Land Institute, Investor and Developer Membership Database (2005); and

- PikeNet, Developer/Investor Directory of Commercial Real Estate (2005).

The data from these sources were combined and filtered to ensure that a survey instrument was sent to only one person, the chief real estate investment officer, at each organization. An organization was excluded if the name of its chief investment officer could not be identified. Consequently, the survey was sent only to named individuals who were best able to comment on their organization's practices. To help ensure frank disclosure, participants were asked not to report their company's name.

Exhibit 1 provides demographic information about the respondents. Of the one hundred eighty-eight completed questionnaires returned (a $23 \%$ response rate), 32 are

VOLUME 11, NUMBER 1, 2008 


\begin{tabular}{llcc} 
& & \\
& Eespondent Summary & \\
& $\begin{array}{l}\text { Companies } \\
\text { Surveyed }\end{array}$ & $\begin{array}{c}\text { Companies } \\
\text { Responding }\end{array}$ & $\begin{array}{c}\text { Response } \\
\text { Rate }\end{array}$ \\
\hline Panel A: Company Type & & & \\
\hline Institutional Investor & $106(13 \%)$ & $32(17 \%)$ & $30 \%$ \\
Investor/Developer & $701(87 \%)$ & $156(83 \%)$ & $22 \%$ \\
Total & $807(100 \%)$ & $188(100 \%)$ & $23 \%$ \\
\hline & & Institutional & Investor/ \\
\hline Panel B: Portfolio Market Values & & Developer \\
\hline \$5+ billion & $18(10 \%)$ & $8(25 \%)$ & $10(6 \%)$ \\
\$1-\$4.99 billion & $44(23 \%)$ & $12(37 \%)$ & $32(21 \%)$ \\
\$200-\$999 million & $60(32 \%)$ & $5(16 \%)$ & $55(35 \%)$ \\
Below \$200 million & $55(29 \%)$ & $1(19 \%)$ & $49(31 \%)$ \\
Not reported & $11(6 \%)$ & $188(100 \%)$ & $10(6 \%)$ \\
Total & $188(100 \%)$ & $156(100 \%)$ \\
\hline
\end{tabular}

from institutional investors and 156 from private investors and/or developers. The respondents were associated mainly with large-sized organizations. It is worth noting that the results are not sorted by portfolio market value because there were very few noticeable differences in the responses when sorted by this parameter. The important differences that were noted are mentioned, where appropriate.

\section{Results}

The key to making a good real estate investment decision is to apply experience, good judgment, and creativity in a sophisticated decision-making process. The results of this study do not provide evidence of the quality of the respondents' experience, judgment, and creativity. Rather, the results focus on the use of an investment decision-making process that includes the following stages: setting strategy, establishing return/risk goals, searching for investment opportunities, forecasting expected returns, evaluating forecast returns, assessing risk, adjusting for risk, decision-making, implementing accepted proposals, and auditing operating performance.

Panel A of Exhibit 2 indicates that the respondents consider searching for investment opportunities, forecasting expected returns, establishing return/risk objectives, and evaluating forecasted returns as the most important stages in the decision-making process. Auditing operating performance is considered the least important stage. 


\section{Exhibit 2 \\ Degrees of Importance of Stages, Evaluation Measures and Investment Opportunity Factors}

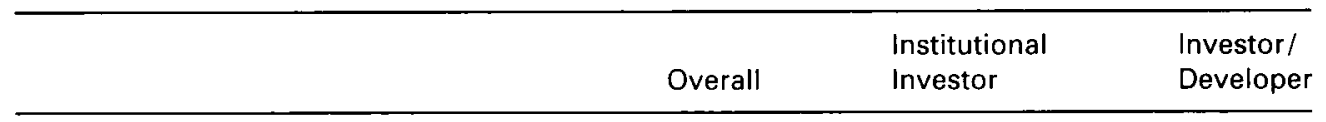

Panel A: Degree of Importance of Stages in Investment Decision-Making Process ${ }^{a}$

\begin{tabular}{llll}
\hline Stages & & & \\
Setting strategy & 2.3 & 2.6 & 2.3 \\
Establishing return/risk objectives & 2.5 & 2.6 & 2.4 \\
Searching for investment opportunities & 2.8 & 2.8 & 2.8 \\
Forecasting expected returns & 2.7 & 2.5 & 2.8 \\
Evaluating forecasts & 2.5 & 2.5 & 2.5 \\
Assessing and adjusting for risk & 2.4 & 2.2 & 2.5 \\
Decision-making & 2.4 & 2.3 & 2.4 \\
Implementing accepted proposals & 2.3 & 2.3 & 2.3 \\
Auditing operating performance & 1.7 & 1.8 & 1.7 \\
\hline
\end{tabular}

Panel B: Degree of Importance of Factors When Searching for Investment Opportunities ${ }^{b}$

\begin{tabular}{llll}
\hline Factors & & & \\
Individual project & 2.9 & 2.7 & 2.9 \\
Strategic & 2.2 & 2.4 & 2.1 \\
Portfolio & 2.0 & 2.2 & 2.0
\end{tabular}

Panel C: Degree of Importance of Evaluation Measures ${ }^{c}$

\begin{tabular}{llll}
\hline Evaluation Measure & & & \\
Internal rate of return & 3.7 & 3.8 & 3.7 \\
Cash-on-cash rate of return & 3.5 & 3.6 & 3.5 \\
Net present value & 2.8 & 3.0 & 2.7 \\
Payback & 2.3 & 1.8 & 2.4 \\
Equity dividend rate & 2.1 & 2.5 & 2.0 \\
Accounting return on investment & 2.0 & 2.5 & 1.9 \\
Gross income multiplier & 1.7 & 1.8 & 1.7 \\
Real option valuation & 1.5 & 1.3 & 1.5 \\
Broker's rate of return & 1.2 & 1.2 & 1.2
\end{tabular}

\section{Notes:}

a Degree is mean score on scale of one (low) to three (highest).

${ }^{b}$ Degree is mean score on scale of one (low importance) to three (high importance).

${ }^{c}$ Degree is mean score on scale of zero (not considered) to four (highest).

The results also suggest that institutional investors place greater importance on strategy and establishing quantified risk and return goals than do private investor and/ or developer respondents. Conversely, private investor and/or developer respondents place greater importance on forecasting expected returns than do institutional investor respondents. 


\section{Setting Strategy and Searching for Investment Opportunities}

Performing a strategic analysis and setting strategic investment goals help focus the search for appropriate investment opportunities. Most respondents (84\%) have strategic investment goals. This is the same outcome as reported by Farragher and Kleiman (1996). This suggests that the acquisition specialists at most of the responding companies begin their search processes only after the organization's investment strategy has been established.

When searching for investment opportunities, the data in Panel B of Exhibit 2 suggest that the respondents see strategic factors as more important than portfolio factors, but less important than individual project factors. Also, institutional investor respondents place greater importance on strategic factors than do private investor and/or developer respondents. Finally, respondents with portfolio market values in excess of $\$ 5$ billion place greater importance on strategic and portfolio factors than do respondents as a whole.

\section{Establishing Return/Risk Objectives}

Investors should establish minimum required-rate-of-return and maximum acceptable risk objectives consistent with their strategic goals. These return and risk objectives should be quantified to provide the communication precision necessary to keep the entire organization on track. The results show that $79 \%$ of the respondents (consistent with $83 \%$ reported in 1996 ) have a quantified minimum required rate of return objective, but a much smaller percentage at $44 \%$ (and much lower than the $64 \%$ result reported in 1996) have a quantified maximum acceptable risk standard. An obvious implication of these data is that real estate investment companies need to improve their consideration of risk, both in the strategic and risk and return goal setting phases of their investment decision-making process. This implication is supported by the responses to questions that inquire into the practices used to assess and adjust for risk.

\section{Forecasting Expected Returns}

Once a strategically viable investment opportunity is identified, an analyst needs to forecast the amount and timing of the expected returns. The data in Panel A of Exhibit 3 suggest that most respondents $(56 \%)$ forecast returns over the expected holding period of each individual investment, rather than over a standard holding period (44\%) for all investments. Private investor and/or developer respondents are more likely to forecast over the expected holding period of each individual investment opportunity and institutional investor respondents are more likely to forecast over a standard time frame. For respondents that forecast returns over a standard time period, the average period is 7.5 years. These results show a decrease in the use of a standard time frame and an increase in the average time period when compared to Farragher and Kleiman (1996). 
Exhibit 3

Forecasting Returns, Risk Analysis \& Diversification

\begin{tabular}{llllll}
\hline & 2005 & & & 1996 \\
\cline { 2 - 4 } \cline { 5 - 6 } & & $\begin{array}{l}\text { Institutional } \\
\text { Onvestor }\end{array}$ & $\begin{array}{l}\text { Investor/ } \\
\text { Developer }\end{array}$ & & $\begin{array}{l}\text { Farragher \& } \\
\text { Kleiman }\end{array}$ \\
\hline
\end{tabular}

Panel A: Forecasting Returns

Company Forecasts Returns Over:

Expected holding period of investment

Standard period for all investments

\begin{tabular}{rrrr}
$56 \%$ & $41 \%$ & $59 \%$ & $25 \%$ \\
$44 \%$ & $59 \%$ & $41 \%$ & $75 \%$ \\
7.5 & 7.8 & 7.6 & 6.7 \\
& & & \\
$98 \%$ & $100 \%$ & $97 \%$ & $94 \%$ \\
$56 \%$ & $50 \%$ & $57 \%$ & $24 \%$ \\
$89 \%$ & $88 \%$ & $90 \%$ & $60 \%$ \\
\hline
\end{tabular}

Return Forecasts Include:

Annual operating returns

Refinancing returns

Residual (disposition) returns

rns

Panel B: Risk Analysis Practices

Risk Assessment:

$55 \%$

$66 \%$

$53 \%$

$35 \%$

If Required, Uses the Following:

Sensitivity analysis

Debt coverage ratio

Scenario analysis

Breakeven analysis

Default ratio

Monte Carlo simulation

Beta

\section{$49 \%$}

$44 \%$

$38 \%$

$31 \%$

$7 \%$

$2 \%$

$1 \%$

\section{$6 \%$}

$53 \%$

$53 \%$

$22 \%$

$6 \%$

$$
0 \%
$$

$9 \%$

\section{$46 \%$}

$42 \%$

$38 \%$

$33 \%$

$8 \%$

$3 \%$

$0 \%$

Risk Adjustment:

Requires quantitative risk adjustment

$41 \%$

$6 \%$

$36 \%$

$35 \%$

If Required, Uses the Following:

Adjust returns

$31 \% \quad 22 \%$

Adjust minimum required return rate

If Required, Adjustment Made:

Intuitively

Using CAPM

Using certainty equivalents

$53 \%$

$5 \%$

$3 \%$

$50 \%$
$6 \%$
$2 \%$

$29 \%$

$24 \%$

$21 \%$

$13 \%$

$5 \% \quad 13 \%$

Panel C: Diversification

\begin{tabular}{llll}
\hline Diversifies Portfolios & $81 \%$ & $94 \%$ & $80 \%$ \\
Diversification Based On: & & & \\
Geographic location & $71 \%$ & $87 \%$ & $68 \%$ \\
Property type & $68 \%$ & $81 \%$ & $66 \%$ \\
Economic location & $37 \%$ & $50 \%$ & $35 \%$ \\
Tenant type & $33 \%$ & $44 \%$ & $31 \%$ \\
Property size & $33 \%$ & $59 \%$ & $28 \%$ \\
Property age & $23 \%$ & $31 \%$ & $22 \%$ \\
\hline
\end{tabular}

VOLUME 11, NUMBER 1, 2008 
Panel A of Exhibit 3 also indicates that most respondents (98\%) forecast annual operating returns, a very high percentage $(89 \%)$ forecast disposition returns, and a significantly smaller percentage $(56 \%)$ forecast refinancing returns. The respondents in this study are more likely to include refinancing and resale return in their forecasts than was reported by Farragher and Kleiman (1996).

Most respondents (72\%) forecast returns on a before-tax cash flow basis, with $16 \%$ using an after-tax cash basis. Of the remainder, $10 \%$ use a before-tax earnings basis, while only $2 \%$ use an after-tax earnings basis. This result is consistent with the findings of earlier studies (Farragher, 1982; and Farragher and Kleiman, 1996). The high use of before-tax cash flows is not surprising for institutional investor respondents or investors and/or developers because both investor types are organized as tax conduits whereby the tax implications of their real estate investments are passed through to the end investors.

\section{Evaluating Forecasts}

After forecasting the amount and timing of expected returns, the forecast values should be translated into an evaluation measure. Over the years, real estate textbooks have presented a plethora of evaluation measures. Some (cash-on-cash rate of return, payback, equity dividend rate, accounting return on investment, gross income multiplier, and broker's rate of return) are based on first-year returns, while others (internal rate of return, net present value, and real option valuation) consider returns over an intended holding period. The prevailing academic thought is that an acceptable evaluation measure should provide for return on, and recovery of, investment on a discounted cash flow basis. Internal rate of return and net present value are two methods that include return-on and recovery-of capital on a discounted cash flow basis.

The results in Panel $\mathrm{C}$ of Exhibit 2 show that respondents perceive the most important evaluation measures to be internal rate of return and cash-on-cash rate of return. Institutional investor respondents place greater importance on the equity dividend rate and accounting return on investment measures than do private investor and/or developer respondents. This may be because shares of institutional investor respondents trade on the stock market, where significant attention is paid to earnings and dividends. Although presented in a different format, Farragher and Kleiman (1996) also found that internal rate of return and cash-on-cash rates of return were the most popular evaluation measures.

Real option models, which provide investors with a tool that allows them to make decisions contingent upon information that will become available in the future (e.g., multi-phase developments), are of low importance to respondents. This may be a result of the technique being in its infancy stage. If so, the tool may grow in importance as real estate investment decision-makers become better informed of its usefulness. Educators could play an integral role in this regard. However, the low usage may be because the inputs cannot be generated. If this is true, option pricing models as presented in the literature may never be used to any significant extent. 


\section{Assessing and Adjusting for Risk}

Because returns are uncertain, investors should assess the degree of uncertainty and calculate a risk-adjusted evaluation measure. Risk assessment can be conducted on a qualitative or quantitative basis. Qualitative risk assessment involves the verbal discussion of risk as contrasted with computerized calculations. The objective is to get a "feel" for uncertainty. Quantitative risk assessment is a procedure that provides a numerical measure of uncertainty. Simple risk assessment tools include debt coverage ratio, default ratio, and breakeven analysis. More complex techniques include sensitivity analysis, scenario analysis, and Monte Carlo simulation.

Results presented in Panel B of Exhibit 3 indicate that quantitative risk assessments are required by $55 \%$ of all respondents and two-thirds of institutional investor respondents. This finding is consistent with our results showing that only $44 \%$ of the respondents have a quantified maximum acceptable risk objective. Sensitivity analysis, debt coverage ratios, and scenario analysis are the most popular quantitative risk assessment techniques. The respondents appear to be more concerned with assessing project risk than portfolio risk. This finding is also consistent with data in Panel B of Exhibit 2 that suggest that, when searching for investment opportunities, individual project factors are more important than overall portfolio factors. The use of quantitative risk assessment has increased since 1996, especially with regard to sensitivity analysis and scenario analysis.

The almost nonexistent use of Monte Carlo simulation is understandable because the technique does not provide an effective way to deal with interdependencies among critical variables. Likewise, the very low use of beta analysis is probably related to practitioners' awareness that beta, an efficient market concept, logically does not apply to the commercial real estate market, which lacks most of the requisites (homogeneity, low transaction costs, quick transaction time, readily available information, etc.) of an efficient market.

Quantitative risk adjustment involves adjusting either the forecast returns or the minimum required rate of return to reflect both the assessed risk and the investor's willingness to bear risk. The returns can be adjusted either intuitively (subjectively) or by using certainty equivalents. The minimum required rate of return can be adjusted either intuitively (subjectively) or by using the Capital Asset Pricing Model (CAPM).

Panel B of Exhibit 3 also shows that only $41 \%$ of the respondents require a riskadjusted evaluation. The percentage of respondents that require a quantitative risk adjustment is slightly higher than was reported in the 1996 Farragher and Kleiman study. When respondents make a risk adjustment, it is almost always done on an intuitive basis. Very little use is made of certainty equivalents or the CAPM.

\section{Decision-Making}

After developing a forecast of the amount, timing, and uncertainty of a project's expected costs and returns, and translating the forecast into a risk-adjusted evaluation

VOLUME 11, NUMBER 1, 2008 
measure, top management needs to decide whether to accept or reject the investment opportunity. Decision-making requires comparing the investment attributes (expected annual rate of return and degree of risk) with the investor's strategic, financial, and diversification goals.

Although the data are not presented, the respondents indicate that individual project factors are more important than strategic or portfolio factors when making the investment decision. This finding is consistent with previously reported findings regarding the relative importance of individual project factors when searching for investment opportunities. Nonetheless, as shown in Panel $\mathrm{C}$ of Exhibit 3, a large percentage of the respondents are concerned about diversification and their diversification most likely reflects geographic location and property type factors.

Webb (1984) and Louargand (1992) investigated the diversification practices of real estate investors. Webb found that only $62 \%$ of respondents attempted to diversify their portfolio and, consistent with the results of this study, reported that diversification was based on geographical location and property type factors. Eight years later, Louargand reported that $92 \%$ of the respondents attempted to diversify their portfolios and that diversification was most often based on property type and economic location factors. Based on the data presented in the current and Webb and Louargand studies, it appears that large real estate investors are keenly aware of the benefits of asset diversification.

\section{Implementing Accepted Proposals}

After deciding to invest in a project, an apparently worthwhile investment may underperform if not implemented on time, at cost, and with the appropriate quality. One way to help ensure successful implementation is to develop an action plan and choose a project manager responsible for carrying out the plan.

As the data in Panel A of Exhibit 4 indicate, $71 \%$ of the responding companies use action plans to implement accepted investment opportunities, and $65 \%$ appoint a project manager to guide the implementation of the investment decision. Institutional investor respondents are more likely to undertake each of these two implementation activities than are investor/developer respondents, with $87 \%$ of institutional investor respondents developing an implementation action plan, and $78 \%$ appointing a project manager to guide implementation of the plan. Although the data are not shown, large companies (portfolio size in excess of $\$ 1$ billion) are more likely to appoint a project manager than are smaller-sized companies. Farragher and Kleiman (1996) reported approximately the same use (72\%) of action plans, but greater use (78\%) of a project manager. The implication for practice is that increased use of implementation action plans and project managers could improve the performance of the investments.

\section{Auditing Operating Performance}

An audit is a review, expressed in terms of the initial assumptions, of the operating performance of implemented investments. It is most effective when performed on a 


\section{Exhibit 4 \\ Activities for Implementation and Performance Auditing}

\begin{tabular}{|c|c|c|c|c|}
\hline & \multicolumn{3}{|l|}{2005} & \multirow{2}{*}{$\begin{array}{l}1996 \\
\begin{array}{l}\text { Farragher \& } \\
\text { Kleiman }\end{array}\end{array}$} \\
\hline & Overall & $\begin{array}{l}\text { Institutional } \\
\text { Investor }\end{array}$ & $\begin{array}{l}\text { Investor/ } \\
\text { Developer }\end{array}$ & \\
\hline \multicolumn{5}{|l|}{ Panel A: Implementation } \\
\hline Develop plan to guide implementation & $71 \%$ & $87 \%$ & $67 \%$ & $72 \%$ \\
\hline $\begin{array}{l}\text { Appoint project manager to oversee } \\
\text { implementation }\end{array}$ & $65 \%$ & $78 \%$ & $63 \%$ & $78 \%$ \\
\hline $\begin{array}{l}\text { Audit operating performance of } \\
\text { implemented investments }\end{array}$ & $55 \%$ & $66 \%$ & $53 \%$ & $61 \%$ \\
\hline \multicolumn{5}{|l|}{ Panel B: Performance Audit } \\
\hline \multicolumn{5}{|l|}{ Audit Conducted By } \\
\hline Investment analysis staff & $28 \%$ & $37 \%$ & $26 \%$ & \\
\hline Operating management & $18 \%$ & $19 \%$ & $17 \%$ & \\
\hline Special audit staff & $9 \%$ & $6 \%$ & $10 \%$ & \\
\hline \multicolumn{5}{|l|}{ Audit Performed On } \\
\hline Annual basis for all investments & $45 \%$ & $59 \%$ & $42 \%$ & \\
\hline Discounted cash flow basis & $30 \%$ & $49 \%$ & $26 \%$ & \\
\hline Earnings basis & $15 \%$ & $28 \%$ & $13 \%$ & \\
\hline
\end{tabular}

regular, rather than optional or crisis, basis and when conducted by independent audit staff who are not involved with forecasting, decision-making, or operating the investment. Auditing is intended to encourage more realistic and honest forecasting because people realize that they will be held accountable for their forecasts. It is also a financial control mechanism that indicates when corrective action is needed to bring an investment to its full potential.

Panel B of Exhibit 4 shows that auditing is required by a surprisingly low percentage $(55 \%)$ of the respondents. This is below the $61 \%$ usage reported in 1996 by Farragher and Kleiman. A higher number of institutional investor respondents $(66 \%)$ require audits. When conducted, audits are most often performed by an organization's investment analysis staff, on a regular basis for all investments. This study identifies auditing as an area that educators could place more emphasis on.

\section{Conclusion}

The results of this investigation indicate that the real estate investment decisionmaking practices of large equity investors have not evolved much since 1996. T-tests were run on the change data for each stage of the decision-making process and the results were not significant for any of the stages ( $p$-values range from .17 to .5 ), thus supporting our premise.

VOLUME 11, NUMBER 1, 2008 
The respondents indicate that searching for investment opportunities, forecasting expected returns, and evaluation of forecasts are the most important stages in the decision-making process, and that individual project factors are more important than strategic and overall portfolio factors. Most respondents have a quantified, minimum required rate of return objective, while a smaller percentage has a quantified maximum acceptable risk standard. Most respondents forecast returns over the expected holding period of each individual investment, rather than over a standard holding period for all investments. Almost all respondents include annual operating and disposition returns as part of their forecast, but a significantly smaller percentage considers refinancing returns. Most forecast returns are on a before-tax, cash flow basis. The most important evaluation measures are internal rate of return and cash-on-cash rate of return. Institutional investor respondents place greater importance on the equity dividend rate and accounting return on investment measures than do the respondents as a whole. The respondents appear to be more concerned with assessing project risk than assessing how an asset contributes to portfolio risk. Although there has been an increase in the use of quantitative risk assessment tools, quantitative risk assessment is required by only one-half of the respondents, with sensitivity analysis, debt coverage ratios, and scenario analysis as the most popular quantitative risk assessment techniques. The use of quantitative risk adjustment has increased slightly, but less than half of the respondents require a quantitative risk adjustment. Almost always, risk adjustments are done on an intuitive basis.

Diversification efforts most likely reflect geographic location and property type considerations. Most respondents develop action plans to implement accepted investment opportunities, but a lesser percentage of respondents appoint a project manager to guide the implementation of an action plan. A low percentage of respondents require an audit of operating performance. When an audit is required, it is likely to be on a regular basis for all investments and is generally performed by investment analysis staff rather than by independent audit staff.

These results suggest that while investment decision-making practices are fairly sophisticated, they have not changed much since the Farragher and Kleiman results were published in 1996. This conclusion suggests a need to analyze why more sophisticated practices have not been adopted over the past decade. Future studies need to inquire into the reluctance of practitioners to adopt more sophisticated practices and to consider whether employing sophisticated tools leads to higher return and/or lower risk. Also, research should investigate a global set of real estate investors to be able to report on similarities and differences across investors based in different countries. Furthermore, academics need to analyze what they can do in the classroom to help bring real estate investment decision-making practices up to a "best methods" level.

\section{References}

Farragher, E. Investment Decision-Making Practices of Equity Investors in Real Estate. The Real Estate Appraiser and Analyst, 1982, 48:2, 36-40. 
Farragher, E. and R. Kleiman. A Re-Examination of Real Estate Investment Decision-Making Practices. Journal of Real Estate Portfolio Management, 1996, 2:1, 31-9.

Louargand, M. A Survey of Pension Fund Real Estate Portfolio Risk Management Practices. Journal of Real Estate Research, 1992, 7:4, 361-73.

Page, D. Criteria for Investment Decision Making: An Empirical Study. The Appraisal Journal, 1983, 51:4, 498-508.

National Real Estate Investor. Atlanta, GA, Top 25 Hotel Owners, February 2004; National Multi Housing Council's 50 Largest U.S. Apartment Owners, April 2004; Top 25 Office Developers, July 2004; Top 25 Office Owners, July 2004; Top 25 Industrial Developers, July 2004; Top 25 Industrial Owners, July 2004; Top 25 Industrial Developers, July 2004; “Top 25 Apartment Owners, July 2004.

Pension \& Investments. Top 50 Managers of Real Estate Assets. December 27, 2004.

PikeNer. Developers/Investors Directory of Commercial Real Estate-2005, www.pikenet.com. REITNet. REITs with Equity Investment Focus. February 1, 2005, www.reitnet.com.

Urban Land Institute. Investor and Developer Membership Database. July 27, 2005, www. uli.org.

Webb, J.R. Real Estate Investment Acquisition Rules for Life Insurance Companies and Pension

Funds: A Survey. Journal of the American Real Estate Society and Urban Economics Association, 1984, 12:4, 495-520.

Webb, J. and W. McIntosh. Real Estate Investment Acquisition Rules for REITS: A Survey. Journal of Real Estate Research, 1986, 1:1, 77-98.

Wiley, R. Real Estate Investment Analysis. The Appraisal Journal, 1976, 43:4, 586-92.

VOLUME 11, NUMBER 1, 2008 